\title{
O Custo Benefício da Implementação da Controladoria nas Micro e Pequenas Empresas
}

Jayny Andrade Joaquim ${ }^{1}$; Maria Erilúcia Cruz Macêdo ${ }^{2}$

\begin{abstract}
Resumo: O objetivo desse trabalho é avaliar o custo benefício da controladoria nas micro e pequenas empresas, apresentando a importâncias desses empreendimentos na economia brasileira assim como as dificuldades encontradas para se manter no mercado. Logo, mostrar o conceito e como atua a controladoria nas entidades. Buscando analisar os benefícios gerados e os custos desembolsados. A metodologia realizada para elaboração esse artigo é baseado em pesquisas bibliográficas, elaborados a partir de livros e artigos científicos, a abordagem da pesquisa é de natureza qualitativa. De acordo com realização deste estudo foi observado que a controladoria pode trazer benefícios econômicos, através de controles de processamentos, analise para redução de custo, estratégias e na tomada de decisões. E o custo podem se apropriar de acordo com o porte das empresas. A controladoria pode ser um diferencial competitivo para as micro e pequenas empresas, ajudando na proteção dos ativos e na continuidade da entidade.
\end{abstract}

Palavras chaves: controladoria; custos; benefícios; tomada de decisões.

\section{The Cost Benefit of the Implementation of Controllership in Micro and Small Companies}

\begin{abstract}
The objective of this study is to evaluate the cost benefit of control in micro and small enterprises, showing the importance of these enterprises in the Brazilian economy as well as the difficulties encountered in maintaining the market. Then, show the concept and how the controller acts on the entities. Seeking to analyze the benefits generated and the costs disbursed. The methodology used to elaborate this article is based on bibliographical research, elaborated from books and scientific articles, the approach of the research is qualitative in nature. According to the accomplishment of this study it was observed that the controllability can bring economic benefits, through process controls, analysis for cost reduction, strategies and in decision making. And the cost can be appropriated according to the size of the companies. Controlling can be a competitive differential for micro and small businesses, helping to protect the assets and the continuity of the entity.
\end{abstract}

Keywords: controller; costs; benefits; decision-making.

\section{Introdução}

Os micros e pequenos negócios (MPE's) têm uma significante participação da economia brasileira. De acordo com este contexto, segundo o SEBRAE, o estado de São Paulo que ocupa o maior número de empreendimentos onde 98\% são de MPE's, uma taxa expressiva visto que é responsável por $50 \%$ da geração de salários.

\footnotetext{
${ }^{1}$ Graduanda do Curso de Ciências Contábeis da UNILEÃO. jaynyandradejoaquim@gmail.com

${ }^{2}$ Especialista em Docência do Ensino Superior. erilucia@ leaosampaio.edu.br
} 
A frente dos dados apresentado e desenvolvendo os conhecimentos, é analisado que essas empresas têm dificuldade em se estabelecer no mercado e abrem falência, em média, menos de dois anos após sua criação. Percebe-se que alguns dos motivos que levam a fecharem as portas são a falta de informações, os recursos limitados e falta de acompanhamento das tendências de mercado.

Em vista desses obstáculos apresentados das MPE`s, faz-se necessário um estudo para aprofundar os conhecimentos acerca do custo benefício da controladoria nas micro e pequenas empresas para melhoria da gestão, analisando as vantagens e o desembolso gerado para a entidade de menor porte.

Para entender a atuação da controladoria torna-se necessário compreender primeiro: seu conceito, suas funções, como o profissional controller atua e os recursos que são utilizados.

Desta maneira, o exposto artigo tem como objetivo geral avaliar o custo benefício da controladoria nas micro e pequenas empresas; seus objetivos específicos são: demonstrar a importância das micro e pequenas empresas na economia, descrever a contribuição da controladoria nas entidades de menor porte e analisar as dificuldades da implantação de controladoria.

\section{Micro e Pequenas Empresas (MPE'S)}

Pela legislação brasileira as micro e pequenas empresas são definidas pela Lei complementar 123 de 2006:

\footnotetext{
Art. 3- Para os efeitos desta Lei Complementar, consideram-se microempresas ou empresas de pequeno porte, a sociedade empresária, a sociedade simples, a empresa individual de responsabilidade limitada e o empresário a que se refere o art. 966 da Lei $\mathrm{n}^{\circ} 10.406$, de 10 de janeiro de 2002 (Código Civil), devidamente registrados no Registro de Empresas Mercantis ou no Registro Civil de Pessoas Jurídicas, conforme o caso, desde que:

I - no caso da microempresa, aufira, em cada ano-calendário, receita bruta igual ou inferior a $\mathrm{R} \$ 360.000,00$ (trezentos e sessenta mil reais); e

II - no caso de empresa de pequeno porte, aufira, em cada ano-calendário, receita bruta superior a $\mathrm{R} \$ 360.000,00$ (trezentos e sessenta mil reais) e igual ou inferior a $\mathrm{R} \$ 4.800 .000,00$ (quatro milhões e oitocentos mil reais). (BRASIL, 2006)
}

O Serviço de Apoio às Micro e Pequenas Empresas - SEBRAE, também delimitada as MPE's, além do faturamento bruto também inclui conjuntamente os números de colaboradores. 
Tabela 1. Definição de micro e pequena empresa pela receita bruta:

\begin{tabular}{|c|l|l|}
\hline \multicolumn{2}{|l|}{ Porte } & Faturamento Bruto Anual \\
\hline \multirow{2}{*}{ Microempreendedor individual ${ }^{1,2}$} & Até $\mathrm{R} \$ 60$ mil \\
\hline \multirow{3}{*}{ MPE } & Microempresa (ME) & Até $R \$ 360$ mil \\
\cline { 2 - 3 } & Empresa de pequeno porte (EPP) & Acima de $R \$ 360$ mil até $\mathrm{R} \$ 3,6$ milhões \\
\hline
\end{tabular}

Fonte: SEBRAE - SP (2018)

Tabela 2. Definição por número de funcionários:

\begin{tabular}{|l|c|c|}
\hline Porte & Comércio e Serviços & Indústria \\
\hline Microempresa (ME) & Até 9 empregados & Até 19 empregados \\
\hline Empresa de Pequeno Porte (EPP) & De 10 a 49 empregados & De 20 a 99 empregados \\
\hline Empresa de médio porte & De 50 a 99 empregados & De 100 a 499 empregados \\
\hline Grandes empresas & 100 ou mais empregados & 500 ou mais empregados \\
\hline
\end{tabular}

Fonte: SEBRAE - NA (2013)

Ainda no Conselho Federal de Contabilidade - CFC, na resolução nº ${ }^{\circ} .055 / 05$ descreve que as MPEs são empresas que não precisam da publicação da prestação de contas e elaboração das demonstrações para os usuários externos, exceto se tiver negociação de suas ações em mercado.

As micro e pequenas empresas podem variar de definição dependendo da análise, entretanto, em todas mostram que tem menores subsídios que as demais nomenclaturas de empresas.

\section{Importância das MPES no Cenário Brasileiro}

Para Silva e Marion (2013) as MPEs têm uma grande importância no mercado brasileiro, uma vez que, além de produzir bens e serviços, consome uma aceitável mão de obra gerando, assim, riqueza para o país.

Muitos brasileiros têm o desejo de criar o seu próprio negócio para garantir a sua renda, consequentemente, esse sonho colabora para que o país possa juntamente desenvolver sua economia.

De acordo com as últimas pesquisas realizadas em 2018 pelo SEBRAE as micros e pequenas empresas são $98 \%$ dos empreendimentos, distribuídos em $41 \%$ em serviços, $37 \%$ comércio, $12 \%$ indústria, $7 \%$ construções e 3\% agropecuária, no estado de São Paulo, onde se centraliza a maior fluxo de mercado do Brasil. 
Quando se é analisado na geração de empregos o SEBRAE mostra que as MPEs são responsáveis por $50 \%$ da composição salarial, porcentagem bastante significante.

Logo, é visível que os pequenos negócios têm uma grande participação na economia do país e na geração de empregos para as famílias brasileiras.

\section{Aspectos que Dificultam a Gestão das MPES}

"A quantidade de pequenos negócios que nascem é elevada, o número de estabelecimentos que sobrevivem é baixo e a quantidade de pequenas empresas que prosperam é alarmantemente próxima da nulidade”. (FERRONATO, 2015, P.49).

Conforme o SEBRAE (2018), as MPEs têm os menores ciclos de vida, em números isso é a taxa de sobrevivência das micro e pequenas empresas do estado de São Paulo que é de 76,3 que equivale a cada 4 empresas 1 abrem falência antes dos dois anos.

Como parte da comunidade empresarial, as pequenas empresas contribuem inquestionavelmente para o bem-estar econômico da nação, porque geram mais empregos do que as grandes corporações. Consequentemente, para benefício da sociedade nacional e da economia brasileira, neste país onde moram mais de trinta milhões de almas vivendo na miséria, o desafio a partir de agora é debater o futuro dessas empresas calcado em cima do conceito de perpetuidade. (FERRONATO 2015, p.22)

Há vários aspectos que podem atravancar esses pequenos negócios, Silva e Marion (2013) destacam alguns deles como:

- Burocracias e altas cargas tributarias: Exigências do governo excessivas para o porte da empresa.

- Pouco capital: Por serem de um mercado menor, seus recursos não limitados.

- Não tem acesso a relatórios financeiros e contábeis mais elaborados para a tomada de decisões: Não tem um auxílio da contabilidade de forma mais completa, que atende geralmente só os serviços fiscais.

- Pouca inovação tecnológica: Tem certa resistência a implantar métodos mais sofisticados.

Segundo Figueiredo e Caggiano (2008), para a sobrevivência, as empresas devem adaptar-se as mudanças com capacidade de qualificar as decisões que foram tomadas no passado em busca das melhores para o presente e futuro.

Conceituado que o mercado se encontra em concorrência acirrada, onde os primeiros a encerrarem suas atividades são os micros e pequenos empreendedores, é fundamental haver bons recursos e gestão de qualidade para garantir o sucesso dessas entidades. 


\section{Planejamento e Custos Operacionais}

Para Figueiredo e Caggiano (2017) o planejamento é a base para o gerenciamento, para que possa haver o sucesso das operações necessárias com uma visão de futuro na tomada de decisões.

De acordo com Castor (2009), o planejamento estratégico deve ser aplicado a todas as escalas de empresas, o que irá mudar é os instrumentos a serem utilizados.

O planejamento é visto como um aparato para empresas de grande porte, todavia, todos os empreendimentos precisam para ter um norteamento do que é primordial para alcançar suas metas esse desenvolvimento ou até mesmo para que o funcionamento se mantenha no mesmo nível de qualidade.

Segundo Souza (2009) todas as operações de negócios resultam em custos que é o valor o qual se consome para obtenção de um recurso, ele pode ser um custo direto onde se é observado de maneira nítida seu valor ou um custo indireto onde não pode ser mensurado de forma habitual.

Grepaidi (2017) ressalva que a estratégia de custo é fundamental para atingir o desempenho desejado do negócio, também explica que definir o preço do produto pelos seus custos pode ser um erro, que o os custos devem ser baseados do preço que o cliente está disposto a pagar.

Em uma época de grande concorrência os preços acabam se dando de forma quase tabeladas, no entanto, é importante observar os custos para a definição do preço de venda e do serviço prestado, com destino de operar de forma que traga um rendimento viável.

Deste modo, ao analisar no âmbito das micro e pequenas empresas o planejamento e controle de custos acaba sendo uma estratégia de negócio, pois a utilização desses recursos pode trazer um diferencial diante da concorrência.

\section{Controladoria}

\section{Origens e Conceito}

Segundo Schmit, Santos e Martins (2014) a controladoria surge aparte das grandes corporações norte americanas com a revolução industrial quando ocorreu aumento e a complexidade em suas produções no século XX. Desde então, elevou-se a necessidade do controle nos sistemas. 
A globalização trouxe junto com ela processos inovadores que tem uma rotatividade muito alta, deste modo, acabou trazendo novos desafios para as entidades controlar todos os procedimentos realizados nas suas atividades.

De Acordo com Padoveze (2013) a Controladoria é a Evolução da contabilidade. Ressalta ainda que a controladoria é a utilização da ciência contábil em sua forma integral.

Já Pitiá (2011) afirma que a atuação da controladoria não é do sistema contábil. Ela tem um alcance maior que se transformou em um banco de dados, assim atuando de forma mais ampla.

Bras (2011) enfatiza que a controladoria pode ser usada na gestão da empresa para dar suporte nas tomadas de decisões mais adequadas para necessidade da mesma.

Entende-se que a necessidade de gerar informações de forma mais rápidas e de qualidade deu espaço ao surgimento da controladoria que efetua como ferramenta de gestão, para que possam utilizar os dados dos sistemas como contábil, financeiros e de produção para que haja um funcionamento eficaz.

\section{Funções da Controladoria}

A controladoria atua em diversas funções dentro da entidade procurando examinar se os fatores internos estão de acordo com o planejamento proposto pela empresa e se os fatores externos possam vim afetar suas atividades.

Segundo Nascimento e Reginato (2015) a controladoria tem a função de estabelecer a efetividade das decisões tomada, confrontando as metas estabelecidas e atingidas, por meio de relatórios que contenham informações dos eventos passados e presentes.

Morante e Jorge (2008), Schmidt e Santos (2009) estabelecem como algumas das funções da controladoria:

- Elabora planejamentos orçamentários: Relatórios para nortear o orçamento que deve ser seguido na entidade.

- Fiscalizar da tributação da empresa: Analisar se estão conforme a legislação vigente.

- Verificar o cumprimento dos procedimentos adotados: Controle dos protocolos a serem seguidos.

- Gera informações para investimentos: Elabora informativos da situação da empresa.

- Verificar os relatórios financeiros: Consultar a fidedignidade dos relatórios.

- Apuração dos custos de produção e vendas: Calcular os custos dos produtos e as despesas. 
Schmidt, Santos e Martins (2014) destacam que as funções podem aumentar quando for entidades de menor porte, em razão de seus recursos serem mais limitados e não poderem contratar um controle para cada função, logo, o mesmo controller irá atuar em todas as áreas da empresa.

Em todas as atividades estabelecidas percebe-se que a controladoria está sempre ligada à busca de melhoria contínua da entidade onde uma função pode ser complementada por outra em destino ao aperfeiçoamento da informação.

\section{Controller}

O Controller é o profissional que atua como responsável para reunir informações ágeis e tempestivas para que a gestão tenha uma avaliação do desempenho.

Para Nascimento e Reginato (2015) esse profissional não basta ter só conhecimentos técnicos que serão exercidos, mas também, deve ter atrativos pessoais como visão crítica, ética profissional e capacidade de liderança para interagir com os gestores.

As empresas procuram mais o profissional de contabilidade para exercer esse papel visando que tem um conhecimento aprofundado no patrimônio e tem conhecimentos de informações econômico-financeiras que pode auxilia na tomada de decisões.

\footnotetext{
Essas atividades tem sido desempenhadas por vários profissionais, entretanto, percebe-se uma tendência, no momento da criação de um departamento de controladoria, de que profissionais da área de contabilidade tem sido os preferidos, especialmente após a crescente demanda de muitas entidades por controles internos e por informações contábeis e gerenciais. (SCHMIDT, 2009, p.40).
}

Pitiá (2011) destaca que o controller não faz controle, no entanto, tem a responsabilidade de estabelecer monitorizações de controle que auxiliarão os responsáveis pelas demais áreas a qualificar o desempenho de suas atividades.

Desta forma, o controller deve ter um bom entendimento na área de atividade para que possa ter uma melhor direção de onde deve atuar e quais os procedimentos devem ser adotados.

\section{MPE'S e a Controladoria}

Independente do porte da empresa é necessário que haja um controle desde a produção e venda até o faturamento da entidade para dar continuidade e se manter em uma boa posição no mercado. 
Segundo Figueiredo e Caggiano (2013) o objetivo de um negócio privado, em uma economia competitiva, é obter o maior lucro possível desde que este não seja inconsistente com o crescimento de longo prazo da companhia e com os padrões éticos da sociedade.

Nos grandes negócios é comum haver um controle, já nas micro e pequenas empresas a controladoria ainda enfrenta uma resistência para sua atuação, visto que seus faturamentos são menores e sua gestão, geralmente, é dada pelos próprios sócios onde podem contrapor inovações para seus negócios.

"Uma das principais funções importantes do controller para as pequenas e médias empresas é a análise dos custos e o auxílio para a formação do preço de venda dos produtos e serviços". (GARCIA, 2010, p.5)

Por consequente, com o ambiente econômico da atualidade, a controladoria se faz necessárias em todos os portes de empresas para que esses empreendimentos possam atuar com maior segurança de mercado e alavancar o micro empreendimento.

\section{Custo Benefício da Controladoria}

\section{Implementação da Controladoria}

Segundo Anagusko (2018) a controladoria deve ser conforme o porte da entidade, visando os seus proventos futuros e o custo da implementação.

Nas micro e pequenas empresas, sua administração tem ligação direta com os sócios proprietários ou até mesmo é exercida por os mesmos, deste modo, sua controladoria pode ser de forma simplificada, mas que atenda às necessidades.

\footnotetext{
Com o intuito de acompanhar a performance das firmas menores, neste momento estamos propondo duas réguas de medidores. Não mensurar implica na impossibilidade de analisar e de controlar. Nessa direção, duas variáveis de verão ser repensadas por parte dos donos das pequenas firmas e dos responsáveis éticos dos escritórios de contabilidade: os primeiros precisam apropriar-se de conhecimentos; os segundos necessitam prestar consultoria e remeter sistema- tipicamente informações úteis e oportunas aos pequenos dirigentes. (FERRONATO, 2015, p. 228)
}

Em frente a uma concorrência acirrada, ferramentas de qualidade para tomada de decisões são de suma importância. Para Santos e Ponte (1998) são as decisões tomadas em todos os níveis da empresa que definem se os recursos estão sendo bem utilizados.

Para Nascimento e Reginato (2015) a implementação da controladoria irá trazer meios que auxiliaram aos gestores ter uma boa visão do funcionamento da empresa e tomar as decisões corretas. 
Por deterem menos recursos as MPEs se limitam as inovações do mercado. No entanto, a capacidade de desenvolvimento pode ser adequada para todos os portes de empresas, trabalhando para a melhoria dos bens já existente na organização.

\section{Tecnologia da Informação e a Controladoria}

De acordo com Schmidt, Santos e Martins (2014) as funções da controladoria passaram por mudanças no último século, principalmente devido as inovações tecnológicas que trazem as informações de forma mais rápida possibilitando ao profissional controller atuar em diversas áreas.

Rezende e Abreu (2014) conceituam a Tecnologia da Informação na visão de gestão como recursos tecnológicos e computacionais para geração de informação. Para sua efetividade é crucial a análise da viabilidade considerando a ótica da realidade financeira da empresa e adequação das necessidades da empresa.

A tecnologia da informação - TI vem estando cada vez mais presente no ramo empresarial como ferramenta nos processos de produção e administração para o aumento da eficiência na elaboração.

\footnotetext{
Algumas organizações têm adotado a TI para aumentar o controle de seus processos, e aumentar a centralização das decisões. Outras, com a adoção dos mesmos recursos de TI, fortalecem a descentralização e a autonomia, promovendo maior envolvimento da força de trabalho. (CONGALVES, 2019, p.8).
}

Segundo Hayes (2008) o TI muda constantemente com a evolução do mercado podendo trazer sempre novos sistemas de trabalho, respondendo em tempo hábil e facilitando a comunicação entre os usuários.

O sistema de TI possibilita as empresas a terem um controle através dos registros de eventos como compras e vendas, estoque disponível, faturamentos e datas efetuadas, entre outros. Ainda é possível adaptar o custo da implementação de TI de acordo com as necessidades da empresa. Logo, as micro e pequenas empresas têm um fluxo menor isso gera um custo menor também.

\section{Consultorias em Controle}

Com a evolução da contabilidade o profissional dessa área deixa de atuar só nas obrigações tributarias e passa a participar diretamente na tomada de decisões da empresa. Portanto, a empresa pode contar com o auxílio do contador para a gestão dos seus pequenos negócios usando essa poderosa ferramenta para o seu desenvolvimento. 
Ferronato (2015) destaca que é importante a relação dos proprietários-gestor com a contabilidade para ter uma visão de como se encontra sua posição econômico-financeira em tempo hábil, podendo, dessa forma, utilizar essas informações na tomada de decisões.

De acordo com Salva e Marion (2013) a contabilidade é essencial no negócio, dado que empresas que tem a contabilidade como utensílio de grande importância na tomada de decisões tem visão de um futuro promissor.

Segundo Braz (2011) a controladoria pode ser de forma terceirizada, isto é, pode ser exercida por empresas que oferece os serviços de controle por um determino período de tempo. Sendo, portanto, denominado personal controller aquele que auxilia a gestão ao comprimento do planejamento e apoia a tomada de decisões.

O profissional de controle terceirizado pode ser uma opção para empresas de pequeno porte, de forma a nortear a gestão nos processos necessários para que haja um controle.

Deste modo, a controladoria pode ser desenvolvida por profissionais que prestam consultorias a empresas facilitando a implementação e possibilitando redução de custos.

\section{Metodologia}

Demo (2007) expõe que o método científico sempre está aberto a novos testes, procurando debater, com o intuito de manter em questões e aperfeiçoar a ciência.

Logo, o estudo trata-se de uma aplicação exploratória, baseado em pesquisa bibliográfica, abordando análise qualitativa das informações contidas em livros publicados pelos estudiosos especialistas da área de controladoria e contabilidade, em site e revistas de trabalhos afins, proporcionando o levantamento do assunto em questão.

Pesquisa é o conjunto de procedimentos sistemáticos, baseado no raciocínio lógico, que tem por objetivo encontrar soluções para problemas propostos, mediante a utilização de métodos científicos. (ANDRADE, 2012, p. 109)

O trabalho desenvolve características descritivas, com análise sobre os custos e os benefícios propostos da controladoria nas micro e pequenas empresas, apresentados em trabalhos científicos.

A abordagem buscou qualificar as informações sobre controladoria através de coletas de dados que corresponda com a aplicação da teoria da pratica para identificar os recursos que podem ser utilizados para detalhar da pesquisa. 


\section{Considerações Finais}

O presente artigo demonstrou as definições da micro e pequena empresa no âmbito legal e mercadológico, trazendo sua importância na economia brasileira e também as dificuldades para se manter com a alta concorrência. Logo, a controladoria vem como ferramenta de apoio frente a esses obstáculos e para o seu desenvolvimento.

A controladoria é uma área desconhecida para uma parte dos pequenos empreendedores, no entanto, é através dela que pode ser feito um bom planejamento, apuração de custos, geração de informações para investidores, relatórios financeiros e outros serviços necessários em todas as entidades independentemente do seu porte.

O controller da empresa pode ser tanto um profissional com vínculo empregatício, como terceirizado; e com auxílio de tecnologia das informações ele irá dar suporte de forma mais prática, portanto, o controle pode ser adequando ao custo benefício que trará para a entidade.

Os sistemas de tecnologia da informação (TI) podem armazenar banco de dados que possam gerar relatórios de auxílio para planejamentos de estratégias competitivas para trazer uma posição lucrativa para a organização.

A controladoria externa pode ser a chave para utilizar essas informações de forma mais viável, com a possibilidade de contrato por um tempo determinado que proporciona um custo menor para a entidade.

Considera-se que, diante do atual mercado brasileiro as micro e pequenas empresas também precisam de um sistema de controle de qualidade e o custo benefício dessa ferramenta pode se adequar aos seus recursos e necessidades trazendo um diferencial para esses pequenos negócios que tanto contribuem para o desenvolvimento do Brasil.

Dada a importância dessa temática na contemporaneidade, espera-se que cada vez mais os contadores (estudantes e profissionais) possam se apropriar dessa temática tanto em pesquisa quanto em suas práticas, buscando caminhos inovadores e desafiadores para os profissionais da área.

\section{Referências}

ANDRADE, Maria de. Introdução à metodologia do trabalho científico: elaboração de trabalhos na graduação, $10^{a}$ edição. Atlas, 09/2012. [Minha Biblioteca]. Data Acesso em: 24 de Outubro de 2018. 
ANTUNES, Junico, KLIPPEL, Altair Flamarion, SEIDEL, André, KLIPPEL, Marcelo. Uma Revolução na Produtividade. Bookman, 01/2013. [Minha Biblioteca]. Data de Acesso: 12 de setembro de 2018.

BRAS, G.M. A controladoria no processo de gestão das empresas de pequeno porte e a importância dos controles internos para estas organizações. 2011. Monografia (Especialização em Controladoria), Universidade Federal do Paraná, Curitiba, 2011.

CREPALDI, Silvio Aparecido, CREPALDI, Guilherme Simões. Contabilidade Gerencial - Teoria e Prática, 8 a edição . Atlas, 03/2017. [Minha biblioteca] Data Acesso: 20 de agosto de 2018

DEMO, Pedro. Praticar ciência: Metodologias do conhecimento científico - $1^{\text {a }}$ edição. Saraiva, 10/2007. [Minha Biblioteca]. Data Acesso em: 24 de Outubro de 2018. Disponível em: < http://acervodigital.ufpr.br/handle/1884/38469>. Data Acesso em: 27 de setembro de 2018.

FERNANDES, A. M.; GALVÃO, P. R. A Controladoria como ferramenta de gestão nas micro e pequenas empresas: um estudo da viabilidade e da relação custo benefício. Revista de Tecnologia Aplicada, v. 5, n. 1, p. 3-16, 2016. Disponível em: <http://www.spell.org.br/documentos/ver/41352/acontroladoria-como-ferramenta-de-gestao-nas-m---> Data Acesso em: 23 de Outubro de 2018.

FERRONATO, Airto João. Gestão Contábil-Financeira de Micro e Pequenas Empresas: Sobrevivência e Sustentabilidade, $2^{a}$ edição. Atlas, 03/2015. [Minha Biblioteca]. Data de Acesso 22 de setembro de 2018

FIGUEIREDO, Sandra, CAGGIANO, Paulo Cesar. Controladoria - Teoria e Prática, $5^{\text {a }}$ edição . Atlas, 01/2017. [Minha biblioteca] Data de Acesso: 02 de setembro de 2018

FONTES FILHO, Joaquim Rubens; NUNES, Geraldo Sant Anna. Estrategista de Micro, Pequena e Média Empresa Brasileira Privada. Revisão de Gestão de Negócios, [Sl], v. 12, n. 36, p. 271-288, oct. 2010. ISSN 1983-0807. Disponível em: < https://rbgn.fecap.br/RBGN/article/view/666/636 > . Data de acesso: 03 de outubro 2018.

GARCIA, Alexandre Sanches. Introdução à controladoria: Instrumentos básicos de controle de gestão das empresas, $1^{\text {a }}$ edição . Atlas, 2010.

HAYES, Robert, PISANO, Gary, UPTON, David, WHEELWRIGTH, Steven C. Produção, Estratégia e Tecnologia. Bookman, 01/2008. [Minha Biblioteca]. Data de Acesso: 25 de setembro de 2018

MOLINARO, Carneiro Ramos. Gestão de Tecnologia da Informação - Governança de TI: Arquitetura e Alinhamento entre Sistemas de Informação e o Negócio. LTC, 11/2010. [Minha Biblioteca]. Data de Acesso: 11 de setembro de 2018

MORANTE, Antonio Salvador, JORGE, Timaco. Controladoria: análise financeira, planejamento e controle orçamentário. Atlas, 06/2008. [Minha biblioteca] Data e acesso: 7 de agosto de 2018

NASCIMENTO, Auster Moreira, REGINATO, Luciane . Controladoria: Instrumento de Apoio ao Processo Decisório, $2^{a}$ edição. Atlas, 06/2015. [Minha Biblioteca]. Data de Acesso: 10 de setembro de 2018

PADOVEZA, Clóvis Luis . Contabilidade gerencial: um enfoque em sistema de informação contábil, $7^{\mathrm{a}}$ edição. Atlas, 08/2010. [Minha Biblioteca]. Data de acesso: 26 de setembro de 2018 Clóvis Luis. Controladoria Estratégica e operacional, $3^{\text {a }}$ Edição . Atlas, 2013. 
PINTO, Murilo da silva. Controladoria - Pequenas e médias empresas Terceirização. 2011. Monografia (pós graduação de controladoria e finanças), Universidade Federal do Paraná, Curitiba, 2011. Disponível em: <https://hdl.handle.net/1884/54273.> Data Acesso em: 20 de Outubro de 2018.

PITIÁ, Maria Graça. Controladoria na gestão - $1^{\text {a }}$ edição. Saraiva, 06/2011[Minha biblioteca] Acesso: Data de acesso: 7 de agosto de 2018

REZENDE, denis Alcides, abreu, Aline França de . Tecnologia da Informação Aplicada a Sistemas de Informação Empresariais, 9a edição. Atlas, 01/2014. [Minha Biblioteca]. Data de Acesso: 16 de setembro de 2018

SANTOS, Edilene Santana; PONTE, Vera. Modelo de decisão em gestão econômica.Cad. estudo. São Paulo , n. 19, p. 01-19, Dec. 1998 . Disponível em:<http://www.scielo.br/scielo.php?script=sci_arttext\&pid=S141392511998000300004\&lng=en\&nr $\mathrm{m}=\mathrm{iso}>$. Data de Acesso: 20 de outubro 2018

SCHMIDT, Paulo, SANTOS, José dos, MARTINS, Marco Antônio dos Santos. Manual de Controladoria. Atlas, 09/2014. [Minha Biblioteca]. Data de Acesso 12 de setembro de 2018

Paulo, SANTOS, José Luiz dos. Fundamentos de Controladoria (V.17) . Atlas, 02/2009. [Minha biblioteca] Acesso: Data de Acesso 9 de agosto de 2018

SEBRAE. Serviço de Apoio as Micros e Pequenas Empresas. 2018. Disponível em: http://www.sebrae.com.br/sites/PortalSebrae/ufs/sp/sebraeaz/pequenos-negocios-em-

numeros,12e8794363447510VgnVCM1000004c00210aRCRD. Data de Acesso: 08 de agosto de 2018

SILVA, Antonio Carlos Da, MARION, José Carlos . Manual de contabilidade para pequenas e médias empresas. Atlas, 10/2013. [Minha Biblioteca]. Data de Acesso: 22 de setembro de 2018. Disponível em: http://hidekianagusko.com.br/controladoria-aplicada-as-micro-e-pequenas-empresasno-brasil-artigo-cientifico/ Data de Acesso: 08 de agosto de 2018

SOUZA, Marcos de, DIEHL, Alberto. Gestão de custos: uma abordagem integrada entre contabilidade, engenharia e administração. Atlas, 05/2009. [Minha Biblioteca]. Data de Acesso: 02 de setembro de 2018

VASCONCELOS, R. B. B. de.; OLIVEIRA, M. R. G. de. Determinantes da inovação em micro e pequenas empresas: Uma abordagem gerencial [Versão original]. RAE - Revista de Administração de Empresas, v. 58, n. 4, Julho-Agosto, p.349-364, 2018. http://dx.doi.org/10.1590/S0034-759020180402; Acesso: 03 agosto de 2018.

\section{Como citar este artigo (Formato ABNT):}

JOAQUIM, Jayny Andrade; MACÊDO, Maria Erilúcia Cruz. O Custo Benefício da Implementação da Controladoria nas Micro e Pequenas Empresas. Id on Line Rev.Mult. Psic., 2019, vol.13, n.43, p. 0113. ISSN: 1981-1179.

Recebido: 15/11/2018;

Aceito: $18 / 11 / 2018$ 